\title{
GCU
}

Glasgow Caledonian

University

University for the Common Good

\section{Freeze/thaw performance of polymer modified cementitious mortars exposed to $\mathrm{NaCl}$ solution}

Klemm, Agnieszka; Sikora, Karol Slawomir

Published in:

Restoration of Buildings and Monuments

Publication date:

2012

Document Version

Publisher's PDF, also known as Version of record

Link to publication in ResearchOnline

Citation for published version (Harvard):

Klemm, A \& Sikora, KS 2012, 'Freeze/thaw performance of polymer modified cementitious mortars exposed to $\mathrm{NaCl}$ solution', Restoration of Buildings and Monuments, vol. 18, no. 3/4, pp. 1-8.

\section{General rights}

Copyright and moral rights for the publications made accessible in the public portal are retained by the authors and/or other copyright owners and it is a condition of accessing publications that users recognise and abide by the legal requirements associated with these rights.

Take down policy

If you believe that this document breaches copyright please view our takedown policy at https://edshare.gcu.ac.uk/id/eprint/5179 for details of how to contact us. 


\title{
Freeze/Thaw Performance of Polymer Modified Cementitious Mortars Exposed to $\mathrm{NaCl}$ Solution
}

\author{
K. Sikora* and A. J. Klemm \\ School of Built and Natural Environment, Glasgow Caledonian University, \\ Glasgow, United Kingdom \\ *Corresponding author: K. Sikora, Karol.Sikora@gcu.ac.uk
}

\begin{abstract}
The paper presents part of a larger research project on the effect of alternating long term freezing and thawing cycles on the micro and macro scale properties of cementitious mortars containing superabsorbent polymers (SAP).

This study analyses a relationship between the alterations of cement paste morphology caused by the omnidirectional exposure to freeze/thaw cycles in presence of $\mathrm{NaCl}$ ions. The effect of a number of alternating freezing and thawing cycles on the performance of mature mortars is assessed. Research work focuses on characterization of mortars modified by two different polymers - copolymer of acrylamide and acrylic acid and a polymer based on acrylic acid. Experimental results confirmed a noticeable impact on the mechanical properties and $\mathrm{f} / \mathrm{t}$ performance of mortar mixes. It was noted that the effect of SAP changes over time.
\end{abstract}

Keywords: Cementitious mortars; Freeze/thaw performance; Superabsorbent polymers. 


\section{Introduction}

Increasing expectations and requirements for building materials are nowadays widespread and constantly evolve. Durability and long life cycle, even under severe environmental conditions, are essential evaluation criteria for new high-performance materials. Therefore even more crucial challenge is to fulfil sustainability trends, having in mind ecological, safety and energy consumption considerations.

In order to meet above expectations cementitious composites can be modified by various chemical admixtures, including superabsorbent polymers (SAP). SAPs are crosslinked networks of hydrophilic polymers, mostly based on polyacrylate and polyacrylamide, with a high capacity for water uptake. They can absorb and retain a large amount of water from surroundings (up to 5000 times to SAP weight) even under pressure depending on the crosslink density of the network $[1,2]$. The use of SAP as an admixture for concrete has been extensively described in the work of O. Jensen and P. Hansen [3]. Main advantage of SAP introduction to cement matrix is prevention of self-desiccation by retention of water in mixes with low water to cement ratios. Further studies on the SAP applications in concrete technology as internal curing agent have been carried out and well documented in the literature $[3,4,5]$. Nevertheless, there is still lack of consensus on their ability to enhance concrete performance in adverse service conditions, in particular in freeze/thaw environment. From the practical point of view to obtain overall assessment of these admixtures, the effect of de-icers on cementitious materials should be investigated. One of the most popular de-icer in a common use is chloride based de-icer $\mathrm{NaCl}$.

Sodium chloride solution may deteriorate cement matrix by chemical and physical reactions. $\mathrm{NaCl}$ in combination with water can reduce integrity and strength of cement matrix and further the propagation of moisture [6]. In principle, free water progresses to zones with high salt content through the process of osmosis increasing hydraulic pressure. On the other hand de-icer with appropriate concentration may be beneficial for freeze/thaw resistance by lowering the temperature when water turns into ice.

Continuous release of water during the process of hydration achieved by addition of SAP may prevent the self-desiccation and in consequence mitigates destructive effects of freezing and thawing [3]. The empty pores are the result of water consumption during the hydration process of cement. The porosity is mainly determined by the amount and particle size distribution of SAP and the water absorption characteristics. Additionally, it is expected that part of irregular capillary pores can be replaced by larger spherical voids formed by saturated polymers [7]. The importance of polymers particles is based on assumption that SAP forms systems of fine, evenly distributed pores, which are filled with swollen polymers in fresh or young cement paste, but then leave empty cavities at later ages. Therefore, after drying out, in the collapsed stage SAP creates air filled pores, which may act similarly to air-entrained pores. However, SAP-pore system, unlike the air bubbles obtained by air-entrained agent application, is very robust and results in a high predictability of its properties and durability to the processing and transport [8]. SAP affects the air content of fresh concrete mixes and consequently porosity of hardened concrete matrix. During mixing small air bubbles may adhere to polymers surface and increase air content [9].

In the light of the above considerations a comprehensive research program is essential to verify available data and enable the formulation of deterioration models. This paper aims to address the problem by presenting some preliminary investigations.

\section{Materials and Methods}

Portland - fly ash cement CEM II/B-V 32.5R (fly ash max. LOI $7 \%$ ), in accordance with EN 197-1 [10] was used in this study. Cement containing minimum $30 \%$ of fly ash by weight was mixed at $1: 1$ ratio with fine sand $(99 \%$ of particles distributed below $0.6 \mathrm{~mm}$ ). Chemical composition of cement is given in Table 1.

Table 1: Chemical composition of CEM II/B-V 32.5R by oxides by weight percentage.

\begin{tabular}{|c|c|c|c|c|c|c|c|c|c|c|c|}
\hline \multicolumn{10}{|c|}{ Oxides by wt\% } \\
\hline $\mathrm{Na}_{\mathbf{2}} \mathrm{O}$ & $\mathbf{M g O}$ & $\mathbf{A l}_{\mathbf{2}} \mathrm{O}_{\mathbf{3}}$ & $\mathrm{SiO}_{\mathbf{2}}$ & $\mathbf{S O}_{\mathbf{3}}$ & $\mathrm{K}_{\mathbf{2}} \mathrm{O}$ & $\mathbf{C a O}$ & $\mathrm{TiO}_{\mathbf{2}}$ & $\mathbf{C r}_{\mathbf{2}} \mathrm{O}_{\mathbf{3}}$ & $\mathbf{M n O}$ & $\mathrm{Fe}_{\mathbf{2}} \mathrm{O}_{\mathbf{3}}$ & $\mathrm{ZnO}$ \\
\hline 0.00 & 1.33 & 13.13 & 32.69 & 4.11 & 1.26 & 43.48 & 0.56 & 0.08 & 0.07 & 3.29 & 0.02 \\
\hline
\end{tabular}


Table 2: Cement mortar composition \& fresh mortar properties.

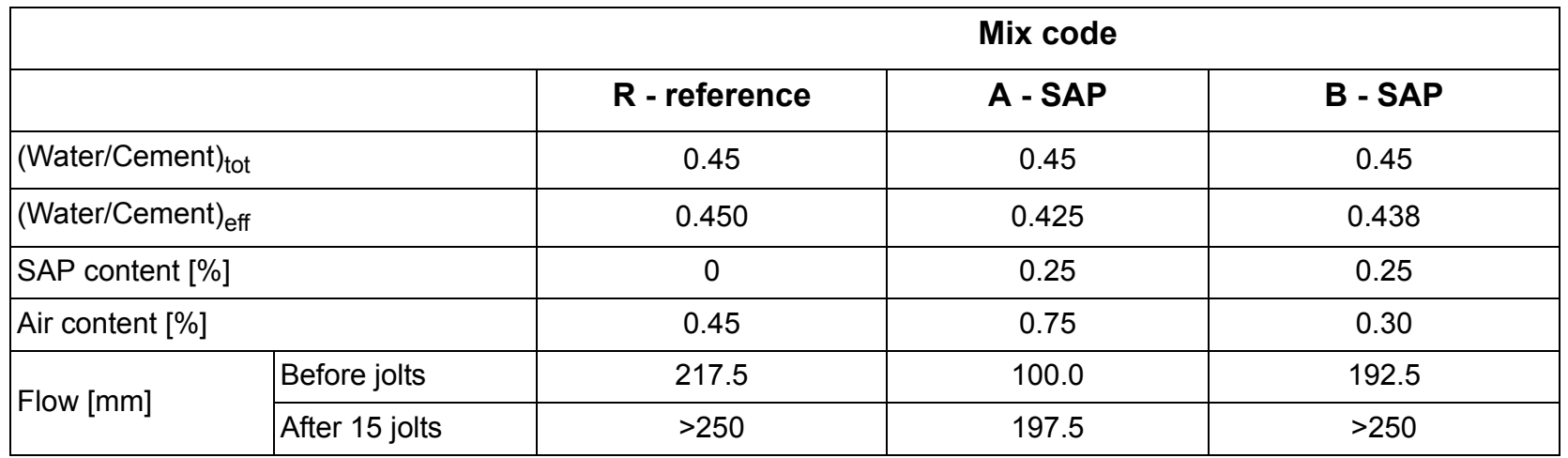

Throughout the investigation a total water to cement ratio of 0.45 was maintained. Two types of the SAP were used in concentration of $0.25 \%$ by weight of cement content. Detailed information about mix composition is presented in Table 2 .

Abbreviations used in this text mean:

- $\mathrm{R}, \mathrm{A}, \mathrm{B}$ - reference samples (without SAP), mixtures with SAP A, mixtures with SAP B

- $(\mathrm{R}, \mathrm{A}, \mathrm{B})-\mathrm{S}$ - mixtures subjected to freeze/thaw cycles and $\mathrm{NaCl}$ solution (after 1 month of initial laboratory curing)

- $(\mathrm{R}, \mathrm{A}, \mathrm{B})-\mathrm{L}$ - mixtures cured in laboratory conditions.
The SAP used in the study, were cross-linked polymers provided by BASF. SAP A is a copolymer of acrylamide and acrylic acid and SAP B is a polymer based on acrylic acid. Products have absorption capacity of $200-250 \mathrm{ml} / \mathrm{g}$ in demineralised water. The absorption in mortar depends on the product and is approximately $10 \mathrm{~g} / \mathrm{g}$ for SAP A and $5 \mathrm{~g} / \mathrm{g}$ for SAP B. Both materials are prepared by grinding and screening to a size of $63-125 \mu \mathrm{m}$, with less than $10 \%$ of smaller particles. The size of particle has a strong implication on absorption/desorption kinetics of SAP [11]. Fig. 1 shows SAP A and SAP B particles in dry and wet conditions. Samples in wet condition have been observed under the SEM after 5 minutes from their contact with water.
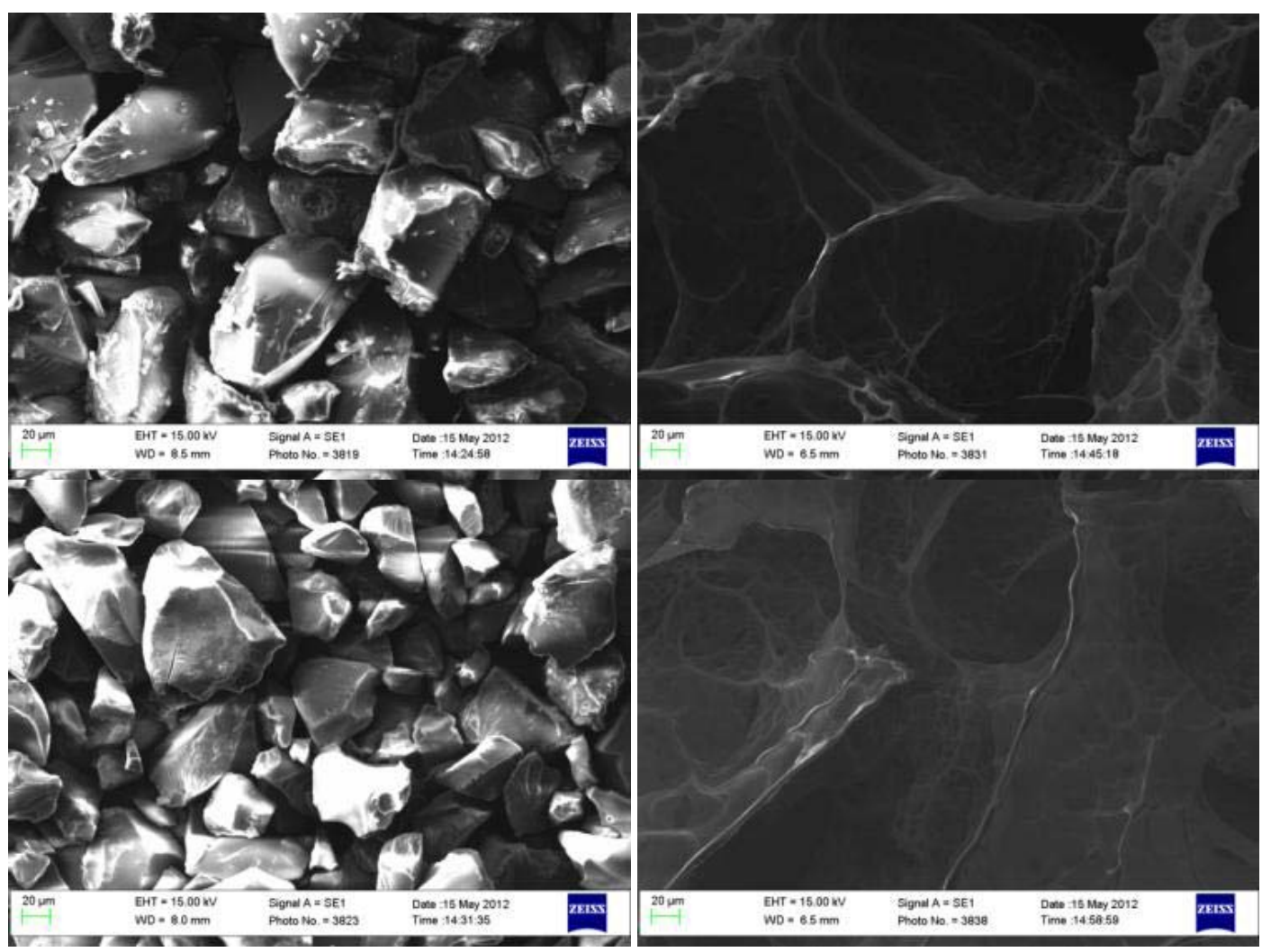

Figure 1: SEM images of dry (left) and wet (right) of SAP A (top) and SAP B (bottom). 
After 1 month of curing in a laboratory conditions ( $40 \pm 5 \mathrm{RH} \%$ and $24 \pm 2{ }^{\circ} \mathrm{C}$; under polythene cover) half of mortar prisms $(160 \times 40 \times 40 \mathrm{~mm})$ were exposed to freezing and thawing cycles with ambient temperature ranging from $-20^{\circ} \mathrm{C}$ to $+20^{\circ} \mathrm{C}$, proceeded by the 24 hours immersion in $3 \% \mathrm{NaCl}$ solution. Samples were subjected to 4 cycles per 24 hours. Every seven days, during a thawing part of cycle, samples were placed for 3 hours into the $\mathrm{NaCl}$ solution. The programmed relative humidity in the Climate Control Chamber was maintained at the level of $80 \%$ at the positive range of temperature. In monthly intervals, $\mathrm{f} / \mathrm{t}$ samples were tested concurrently with those stored in laboratory conditions. The samples have been exposed to the maximum of 360 cycles of $f / t$.

The analyses of mechanical properties were performed using standardized procedures in accordance to BS 1881-119:1983 [12]. Microstructural examination has been carried out with the use of Porosimeter (Micromeritics Autopore IV 9500) and Scanning Electron Microscopy (Carl Zeiss EVO 50).

\section{Results and Discussion}

Experimental program consisted of determination of mechanical properties followed by the MIP and SEM analysis. Analysis of the compressive strength results, presented in Fig. 2, reveal an interesting relationship. In general, addition of SAP A slightly increased and SAP B slightly decreased compressive strength by comparison with reference sample for laboratory curing in all ages. The exposure to freeze/thaw cycles and $\mathrm{NaCl}$ solution insignificantly decreased the strength for all mixes when compared with corresponding lab cured specimens, with the exception of sample R after 3 months and B after 2 months. However, it can be noticed that the ratio of strength reduction (lab curing/climatic chamber curing) was negligible for samples containing SAP B. This polymer decreases the compressive strength of mortars and further exposure to adverse conditions does not affect the strength. In turn, it is apparent that addition of SAP A increases compressive strength which was lowered to the minor extent by exposure to $\mathrm{f} / \mathrm{t}$ cycles. Nevertheless, prolonged deterioration of samples was very limited after the first month.

The results of the total porosity (Table 3 ) indicate rather insignificant influence of Sodium Chloride exposure on the freeze/thaw performance of tested samples. Small decrease in porosity with time was recorded for all lab cured samples that confirmed progress of hydration process. The influence of SAPs manifests itself in an increase of total porosities for lab cured A samples and in a decrease for B samples in comparison with corresponding reference samples. Total porosities for samples subjected to $f / t$ cycles show a tendency to increase, particularly in reference samples, indicating a frost damage.

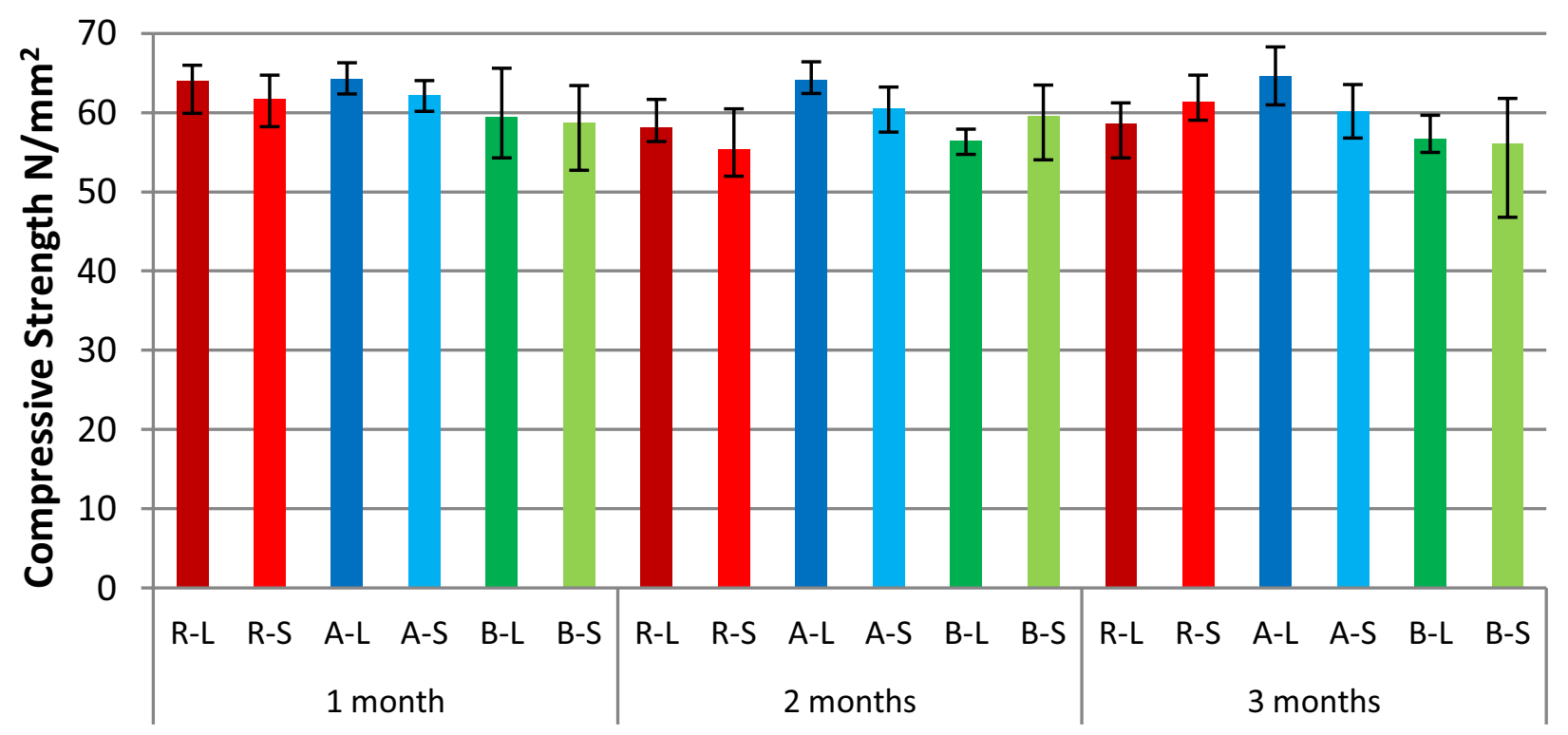

Figure 2: Compressive strength of samples cured in lab conditions in comparison with samples subjected to f/t cycles and $\mathrm{NaCl}$ solution (age corresponds to period of $\mathrm{f} / \mathrm{t}$ curing). 
Table 3: Total porosity of samples [\%]

\begin{tabular}{|c|c|c|c|c|c|c|}
\hline \multirow{2}{*}{ Age } & \multicolumn{6}{|c|}{ Mix } \\
\cline { 2 - 7 } & R-L & R-S & A-L & A-S & B-L & B-S \\
\hline 1 month & 21.45 & 17.84 & 21.49 & 21.44 & 18.75 & 19.75 \\
\hline 2 months & 19.83 & 19.03 & 20.98 & 20.79 & 18.52 & 18.84 \\
\hline 3 months & 19.45 & 19.59 & 20.08 & 21.00 & 16.99 & 19.56 \\
\hline
\end{tabular}

Fig. 3 below presents the results of pore size distribution of all analysed samples. Log differential intrusion vs. pore size diameter curves for samples (R,A,B) subjected to $\mathrm{f} / \mathrm{t}$ cycles and $\mathrm{NaCl}$ solution for 1,2, 3 months in comparison to corresponding samples cured in lab conditions are shown. In general two distinctive pore size ranges can be identified: $30-70 \mathrm{~nm}$ and $200-700 \mathrm{~nm}$.

A strong effect of SAP A after 2 months of lab curing has been noticed. The largest share of pores occurred for diameters of approximately $60-70 \mathrm{~nm}$. This peak decreased with time and moved slightly in the direction of smaller pores 30-50 nm (after 4 months of lab curing). At the same time another small peak has appeared for larger pores, approximately $300-900 \mathrm{~nm}$. SAP A has relatively high water intake and is more stable, resulting in extended period of desorption. It is likely therefore, that the larger pores were created as a result of collapsing SAPs while increase of small pores could be explained by a formation of denser network of CSH gel.

The exposure of SAP A mortars to freeze/thaw cycles and salt resulted in the reduction of small pores peak. The most pronounced changes have taken place during the first month of $f / t$ in the climatic chamber. Prolonged exposure to $\mathrm{f} / \mathrm{t}$ cycles has led to a small move of the peak towards bigger pores. This gives an indication that most changes in microstructure for A samples occurred in first days of $\mathrm{f} / \mathrm{t}$ cycles and a subsequent progressive deterioration of samples was very limited. This observation is in accordance with the compressive strength results, where no major changes have been observed with time.

On the other hand, the effect of SAP B is very limited. Microstructural characteristics of samples containing SAP B were very similar to the reference samples, regardless of curing regime. The prolonged exposure to $\mathrm{f} / \mathrm{t}$ cycles resulted in a slight, but gradual decrease in small pores of diameters of approximately $30-70 \mathrm{~nm}$ and increase in a share of bigger pores, giving an indication of progressive deterioration. Similarities in microstructural char- acteristics of samples B and reference samples could be attributed to the relatively low absorption capacity of SAP B.

Extensive analyses by the Scanning Electron microscopy have confirmed rather limited effect of the exposure to alternating freezing/thawing in the presence of salt. The micro characteristics of reference samples cured 1 month in chamber were very similar to these cured in the laboratory conditions. Fig. 4 shows internal structure of samples subjected to $f / t$ cycles for 1 month and corresponding lab cured samples. In all cases unreacted particles of fly ash were visible and in samples containing SAP A additional voids created by polymer could be identified. Pores that appeared as a result of SAP B addition were not so pronounced.

Comparing all samples after 3 months of curing in the climatic chamber with corresponding lab cured ones it can be noted that samples cured in lab condition have a smaller number of small pores $(30-70 \mathrm{~nm})$. This could be attributed to the restricted availability of water for hydration.

This limited effect of freezing and thawing cycles on mortars may be associated with the presence of $\mathrm{NaCl}$ ions. Although in general, deterioration of internal structure results from ice formation and pressure generation by salt crystals formation, salts may have some positive effects. At some concentrations salts may positively affect the durability of concrete by delaying the ice formation. Even if some ice is formed, the salt concentration in the residual solution will increase and in this way any further ice growth is retarded. Additionally, salts prevent from the capillary effect that occurs only at lower temperatures, and only to lesser extent than by freezing without salts. It should be pointed out that the lowest temperature for salt solution to be in a liquid phase is $-21.1{ }^{\circ} \mathrm{C}$. This temperature is lower than cooling temperature applied in this study. Additionally $3 \% \mathrm{NaCl}$ solution used here is near to the lower limit of deteriorating salt concentrations (2-14\%) [13] and therefore not affecting mortar performance to any significant extent. 

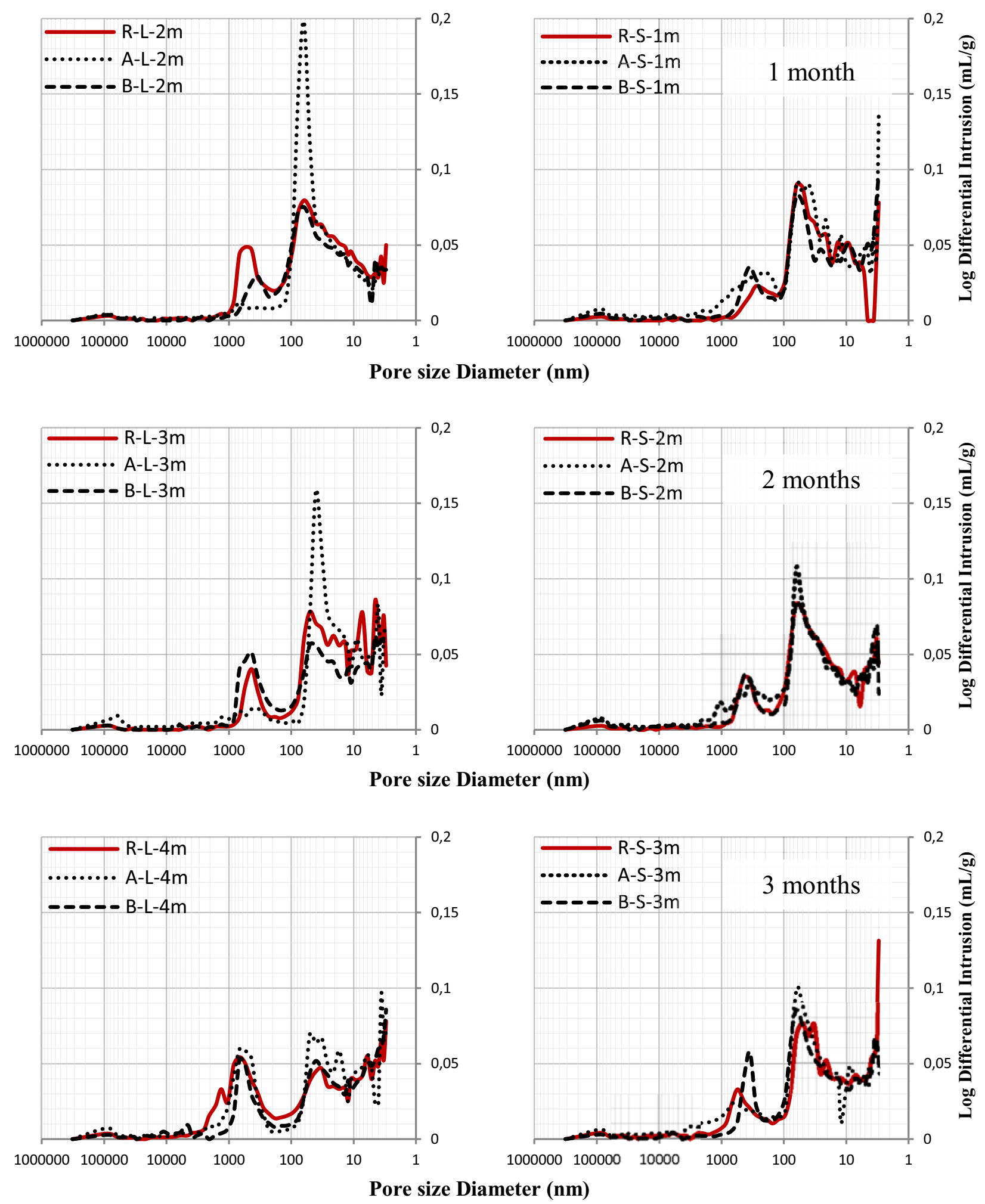

Figure 3: $\quad$ Pore size distributions in samples cured in lab conditions and subjected to f/t cycles after 1, 2 and 3 months (age corresponds to period of $f / t$ curing). 

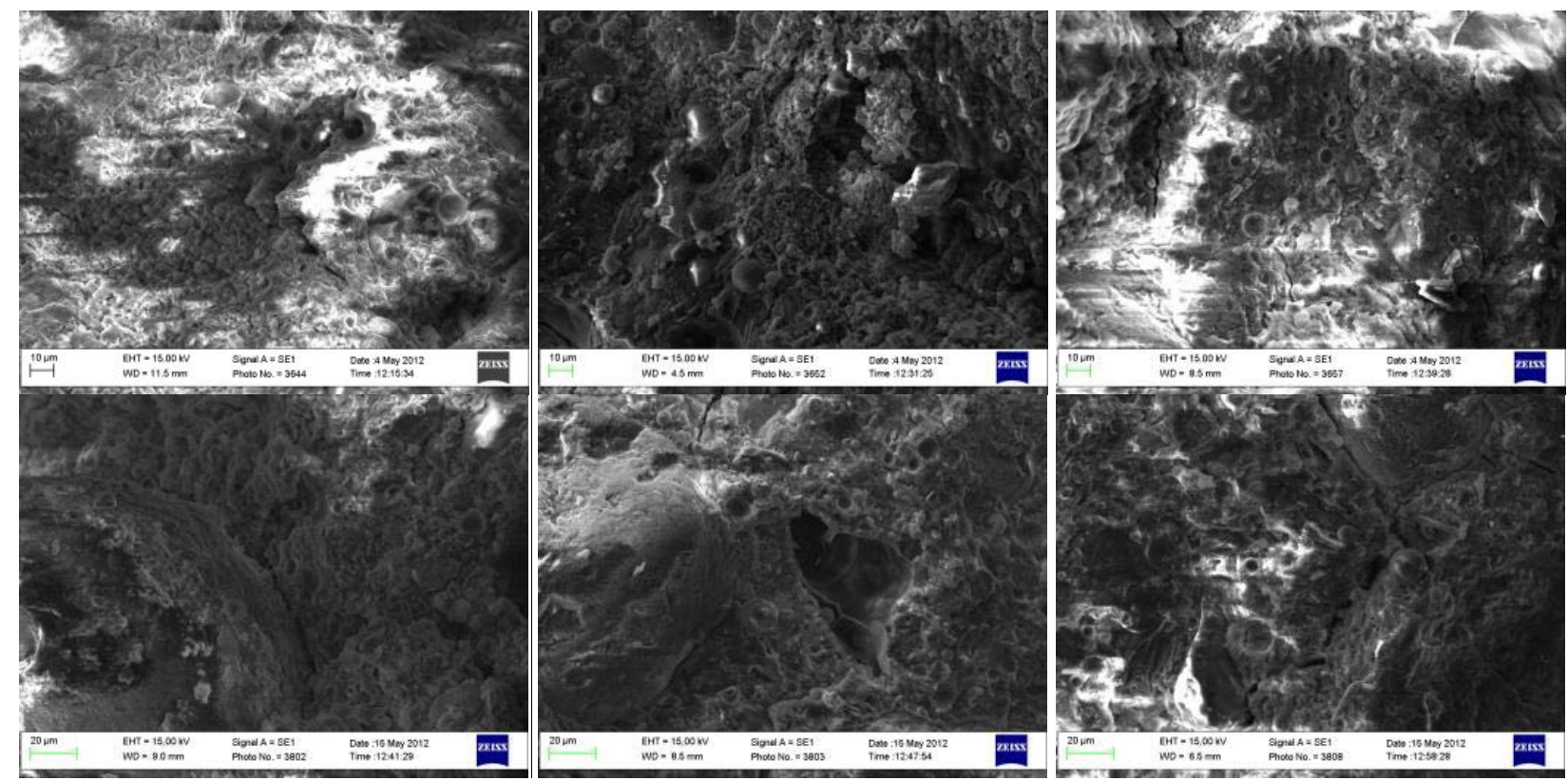

Figure 4: $\quad$ SEM images of samples R, A and B cured in lab conditions (top) and subjected to f/t cycles after 1 month (age corresponds to period of $f / t$ curing).

\section{Conclusions}

Based on presented experimental results the following conclusions can be formulated:

- Superabsorbent polymers have noticeable impact on the mechanical properties of mortars. Although small decrease of compressive strength has been observed for samples subjected to $\mathrm{f} / \mathrm{t}$ cycles and salt exposure, the progressive deterioration of samples after first month was very limited.

- A very strong effect of SAP A, noticeable in early stages of lab curing, diminishes with time. The reduction of that effect is accelerated by the prolonged exposure to freeze/thaw cycles. In contrary, the effect of SAP B is minimal. Analyses of microstructures for SAP B samples and the reference samples showed significant similarities. It may be explained by the significant difference in water absorption rate for different SAPs in cement composites.

- The freezing and thawing cycles and salt exposure had limited effect on mortar performance. However, it might be more pronounced in typical service conditions when composite is subjected to multi-damaging processes - simultaneous exposure to freezing/thawing, external loading, sulphate attack and so on.

\section{Acknowledgements}

Provision of superabsorbent polymers by BASF Construction Chemicals $\mathrm{GmbH}$ for the purpose of this study is gratefully acknowledged.

\section{References}

1. T. Sakiyama, C.H. Chu, Fujii, T. Yano, Preparation of a polyelectrolyte complex gel from chitosan and $\kappa$-carragen and its $\mathrm{pH}$-sensitive swelling, Journal of Applied Polymer Science, Vol. 50, 11 (1993) pp. 2021-2025

2. K.M. Raju, M.P. Raju, Y.M. Mohan, Synthesis and water absorbency of crosslinked superabsorbent polymers, Journal of Applied Polymer Science, Vol. 85, 8 (2002) pp. 1795-1801

3. O.M. Jensen, P.F. Hansen, Water-entrained cement-based materials I. Principles and theoretical background, Cement and Concrete Research, 31 (2001) pp. 647-654

4. H.W. Reinhardt, A. Assmann, Enhanced durability of concrete by superabsorbent polymers', Proc. Int. Symp. Brittle Matrix Composites 9, Warsaw (2009)

5. S. Zhutovsky, K. Kovler, Combined effect of internal curing and shrinkage-reducing admixture on cracking potential of High-strength Concrete, International Conference on Material Science and $64^{\text {th }}$ RILEM Annual Week in Aachen - MATSCI 2010 
6. X. Shi, M. Akin, T. Pan, L. Fay, Y. Liu, Z. Yang, Deicer Impacts on Pavement Materials, Introduction and Recent Developments, The Open Civil Engineering Journal, 3 (2009) 16-27

7. S. Mönnig, P. Lura, Superabsorbent Polymers - An Additive to Increase Freeze-Thaw Resistance of High Strength Concrete, in: Advances in Construction Materials 2007, Part V, 351-358

8. A.E. Brüden, V. Mechtcherine, Multifunctional use of SAP in strain-hardening cement-based composites, International RILEM Conference on Use of Superabsorbent Polymers and Other New Additives in Concrete, Lyngby (2010)

9. H.W. Reinhardt, A. Assmann, S. Mönnig, Superabsorbent Polymers (SAPS) - an admixture to increase the durability of concrete, Microstructure Related Durability of Cementitious Composites, Nanjing (2008)
10. EN 197-1:2000, Cement - Part 1: Composition, specifications and conformity criteria for common cements

11. L.P. Esteves, On the absorption kinetics of Superabsorbent Polymers, International RILEM Conference on Use of Superabsorbent Polymers and Other New Additives in Concrete, Lyngby (2010)

12. BS 1881-119:1983, Testing concrete. Method for determination of compressive strength using portions of beams broken in flexure (equivalent cube method)

13. G.J. Verbeck, P. Klieger, Studies of 'Salt' Scaling of Concrete, Highway Research Board Bulletin (1957)
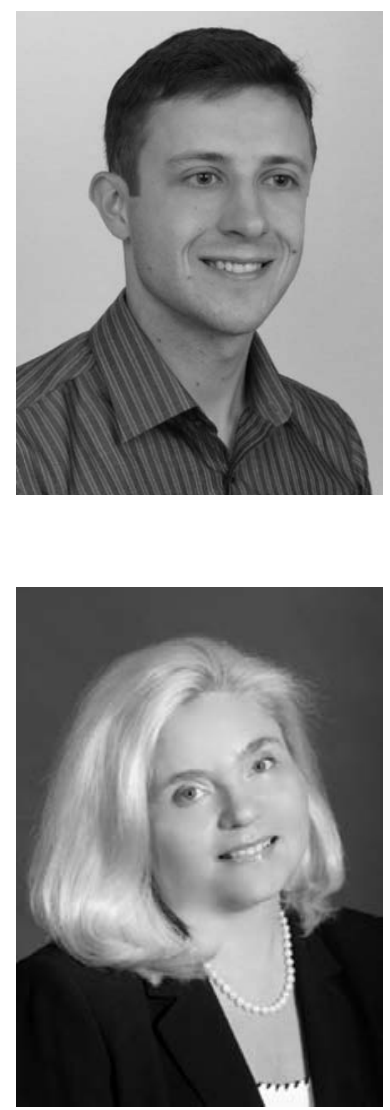

Karol Sikora, MSc (civil eng.), MA (management), is a Research student within the School of Engineering and Built Environment at Glasgow Caledonian University. He is engaged on a programme of research - 'The effect of superabsorbent polymers on freeze-thaw performance of cementitious mortars and plasters', leading to the award of $\mathrm{PhD} . \mathrm{He}$ is a member of Chartered Institute of Building and the President of Research Students' Society at Glasgow Caledonian University. E-mail: Karol.Sikora@gcu.ac.uk

Agnieszka J Klemm, PhD, MSc (civil eng.), is a Reader in construction materials in the School of Engineering and Built Environment, the Glasgow Caledonian University, Scotland. She is a Member of the Institute of Concrete Technology, Chartered Institute of Building and a Fellow of the Higher Education Academy. She is the member of the two RILEM technical committees and an evaluator/reviewer of numerous European research projects (FP7). E-mail: A.Klemm@gcu.ac.uk

Received June 25, 2012 